\title{
Duplex Ultrasonography and its Use in Surveillance Post-EVAR
}

\author{
Danielle M Pineda*, Matthew J Dougherty, Keith D Calligaro and Douglas A Troutman
}

Department of Vascular Surgery, Pennsylvania Hospital, Philadelphia, PA, USA

*Corresponding author: Danielle M Pineda, Department of Vascular Surgery, Pennsylvania Hospital, Philadelphia, PA, USA, Tel: 215-829-5000; Fax: 215-627-3199; Email: Danielle.pineda@gmail.com

Rec date: Jan 20, 2015; Acc date: Feb 18, 2015; Pub date: Feb 20, 2015

Copyright: @ 2015 Pineda DM, et al. This is an open-access article distributed under the terms of the Creative Commons Attribution License, which permits unrestricted use, distribution, and reproduction in any medium, provided the original author and source are credited.

\section{Abstract}

After endovascular aortic aneurysm repair (EVAR), patients require annual surveillance with either CT scan or duplex ultrasonography (DU). These studies should be used to identify patients who require reintervention for EVAR complications. DU, a less expensive and radiation free option, has been shown to accurately predict aneurysm sac size and endoleak. In addition, using criteria of PSV $<300 \mathrm{~cm} / \mathrm{s}$ and PSV ratio $<3.5$, DU can rule out limb stenosis. After a normal post-procedure DU, only $2.2 \%$ of patients require reintervention within the first 3 years suggesting that less frequent follow-up may be utilized. DU is an important tool in the surveillance of EVAR patients.

Keywords: Endovascular aortic aneurysm repair; Duplex ultrasonography; noninvasive; Abdominal aortic aneurysms

\section{Description}

Since the first endovascular aortic aneurysm exclusion (EVAR) in 1991, repair of abdominal aortic aneurysms (AAAs) has shifted from primarily an open approach to approximately $75 \%$ treated today with EVAR in the United States [1]. Despite the improvement in devices and technique, it is estimated that $13-22 \%$ of patients require reintervention after EVAR for limb occlusion, endoleak, infection, and other complications. Therefore, proper surveillance after EVAR is critical to diagnose these problems and prevent severe complications such as rupture and limb ischemia. Surveillance imaging studies must detect endoleaks, monitor growth in sac size, and predict for risk of graft limb occlusion. Currently, the Society for Vascular Surgery recommends annual surveillance with either CT or duplex ultrasonography (DU) if the original post-operative CT scan does not demonstrate any of these concerns [2].

Due to the cost and radiation concerns associated with CT scans, our group has done extensive research on the preferential use of DU done in our ICAVL-accredited noninvasive vascular laboratory for EVAR surveillance. We compared CT scans versus duplex ultrasonography in 199 patients who underwent EVAR between 1998 and 2008, and found comparable sensitivity and specificity between CT scans and DU in the diagnosis of endoleak ( 0.710 vs 0.731 and 0.990 vs 0.991 , respectively). In addition, DU was able to predict aneurysm sac size accurately $(\mathrm{p}<0.001)$. The use of ultrasound resulted in a cost-savings of $\$ 1595$ per patient per year compared to annual CT scans [3]. Based on these findings, DU is a safe alternative to CT scans in the annual surveillance of EVAR, but CT scans should still be used judiciously if questions arise on DU. Endoleaks can lead to increase in aneurysm sac size and rupture. Type 1 and type 3 endoleaks have a high likelihood causing sac growth, and therefore should be repaired when diagnosed. Type 2 endoleaks, on the other hand, can often be monitored without observing sac growth. Since DU can reliably detect endoleak, our group sought a way to distinguish which type 2 endoleaks can be safely followed by duplex, and which should be treated. In our 2010 report, 38 of 278 EVAR patients developed a Type
2 endoleak (14\%). Contradicting previous reports, we found intra-sac flow velocity on DU poorly predictive of the clinical significance of Type 2 endoleaks. However, multiple Type 2 endoleaks niduses, and bidirectional spectral doppler waveforms, were predictive of increased sac diameter [4]. We theorized that patients with these findings may benefit from early treatment of Type 2 endoleak.

Limb occlusion is another complication of EVAR that can lead to ischemic limbs and amputation. We believe that limb stenosis usually precedes limb occlusion, and should be treated when identified. Our 2012 report sought to determine DU criteria for critical limb stenosis in 496 EVAR limbs. Of this cohort, 479 limbs had a peak systolic velocity (PSV) less than $300 \mathrm{~cm} / \mathrm{s}$ throughout the surveillance period, and no occlusions or secondary procedures occurred. Of the $17 \mathrm{graft}$ limbs with PSV $>300 \mathrm{~cm} / \mathrm{s}$, seven developed occlusion and five underwent a prophylactic intervention. The remaining five remained patent over a mean 46 month follow up [5]. We concluded that limb velocities of PSV $<300 \mathrm{~cm} / \mathrm{s}$ and PSV ratio of $<3.5$ predict for longterm graft limb patency, but they should have continued surveillance.

Optimal timing of surveillance studies will be a critical part of postoperative management of EVAR patients going forward. With the increased number of EVARs being performed, annual surveillance can be expensive and inconvenient, but is preferred over missing a complication. In our 2014 report, we hoped to determine whether the follow-up interval can be extended following an initial normal postEVAR DU. We looked at 113 patients with an endoleak or limb stenosis out of cohort of 410 EVAR patients during a 15 year period. Mean follow-up time was 35 months. Of patients with an initially normal DU, only $2.2 \%$ required re-intervention within the first 3 years. However, patients with an initially abnormal DU had a $25 \%$ reintervention rate by 3 years [6]. We concluded that patients with a normal first study may not require repeat DU surveillance for up to 3 years. This study does not determine optimal surveillance interval beyond 3 years. Additional studies support future uses of ultrasound for surveillance of EVAR patients. Contrast enhanced ultrasound (CEUS) is another technique which appears to be gaining popularity in EVAR surveillance. Karthikesalingam et al. specifically studied the detection of type 1 and type 3 endoleaks and found that CEUS and CT scan were specific in the detection of these endoleaks but that DU also had sufficient detection [7]. CEUS has been shown to have a $97 \%$ 
sensitivity and 93\% sensitivity in the detection of endoleaks [8]. Other ultrasound techniques have also been studied. Arsicot et al. evaluated aneurysm sac size after EVAR and found that using volumetric echography shows comparable results to CTA [9].

In conclusion, duplex ultrasonography in an ICAVL accredited laboratory is a safe alternative to CT for the diagnosis of endoleak, limb occlusion, and aneurysm sac growth. DU has the advantages of being a dynamic study with lower cost, no need for IV contrast, and no ionizing radiation. We believe that using DU criteria defined in our previous publications, less frequent surveillance may be appropriate after a normal initial surveillance study (Table 1).

\begin{tabular}{|l|l|}
\hline Duplex Ultrasonography & CT \\
\hline No radiation used & Standard of care for EVAR surveillance \\
\hline More affordable than CT scans & $\begin{array}{l}\text { More reproducible (less operator } \\
\text { dependent) }\end{array}$ \\
\hline $\begin{array}{l}\text { Can frequently be performed in } \\
\text { office setting the same day } \\
\text { physician visit }\end{array}$ & Used in initial EVAR surveillance studies \\
\hline $\begin{array}{l}\text { No contrast needed (especially } \\
\text { important in chronic renal failure } \\
\text { patients) }\end{array}$ \\
\hline
\end{tabular}

Table 1: Advantages of DU compared to CT scans in the surveillance of EVAR patients

\section{References}

1. Kent KC (2014) Clinical practice. Abdominal aortic aneurysms. N Engl J Med 371: 2101-2108.
2. Chaikof EL, Brewster DC, Dalman RL, Makaroun MS, Illig KA, et al. (2009) The care of patients with an abdominal aortic aneurysm: the Society for Vascular Surgery practice guidelines. J Vasc Surg 50: S2-49.

3. Beeman BR, Doctor LM, Doerr K, McAfee-Bennett S, Dougherty MJ, et al. (2009) Duplex ultrasound imaging alone is sufficient for midterm endovascular aneurysm repair surveillance: a cost analysis study and prospective comparison with computed tomography scan. J Vasc Surg 50: 1019-1024.

4. Beeman BR, Murtha K, Doerr K, McAfee-Bennett S, Dougherty MJ, et al. (2010) Duplex ultrasound factors predicting persistent type II endoleak and increasing AAA sac diameter after EVAR. J Vasc Surg 52: 1147-1152.

5. Blom AS, Troutman D, Beeman B, Yarchoan M, Dougherty MJ, et al. (2012) Duplex ultrasound imaging to detect limb stenosis or kinking of endovascular device. J Vasc Surg 55: 1577-1580.

6. Troutman DA, Chaudry M, Dougherty MJ, Calligaro KD (2014) Endovascular aortic aneurysm repair surveillance may not be necessary for the first 3 years after an initially normal duplex postoperative study. J Vasc Surg 60: 558-562.

7. Karthikesalingam A, Al-Jundi W, Jackson D, Boyle JR, Beard JD, et al. (2012) Systematic review and meta-analysis of duplex ultrasonography, contrast-enhanced ultrasonography or computed tomography for surveillance after endovascular aneurysm repair. Br J Surg 99: 1514-1523.

8. Gürtler VM, Sommer WH, Meimarakis G, Kopp R, Weidenhagen R, et al. (2013) A comparison between contrast-enhanced ultrasound imaging and multislice computed tomography in detecting and classifying endoleaks in the follow-up after endovascular aneurysm repair. J Vasc Surg 58: 340-345.

9. Arsicot M, Lathelize H, Martinez R, Marchand E, Picquet J, et al. (2014) Follow-up of aortic stent grafts: comparison of the volumetric analysis of the aneurysm sac by ultrasound and CT. Ann Vasc Surg 28: 1618-1628. 